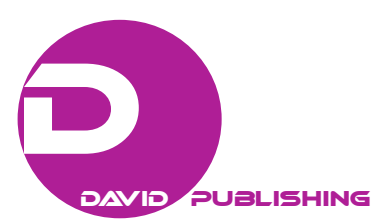

\title{
Introduction of New Method on Engineering Risk Assessment: Engineering Errors and Effects Analysis (3EA)
}

\author{
Mohammad Mahdi Izadi \\ Shahid Beheshti University of Medical Science; Nargan Co., Tehran, Iran
}

\begin{abstract}
Construction and commissioning accidents investigation shows that engineer's errors in basic and detailed phases are the main causes. It will be gained more efficiency of investment when a relevant method is applied for error identification and risk assessment in basic and detailed phases. Most of risk assessment methods are related to construction phase, meanwhile hidden risks that were happen in previous phases cannot be found by these methods. Although HAZOP study can be applied in detail phase but it can help to find process defections. Importance of identifying risks in basic and detailed phases is to apply preventive actions against birth and grows risks. This risk assessment method can reduce costs and improve environmental protection, safety, and reliability of designs. The main purpose of this study is to identify engineer's errors and analyse their HSE effects. The method is applied in seven oil and gas engineering projects in Iran, raising the level of engineer's attention to safety precautions and environmentally-friendly design, reducing the cost of improving the level of safety and environmental protection, improving environmental protection, safety, and design reliability, and improving procedures related to design process and control have been achieved.
\end{abstract}

Keywords: Engineering Errors and Effects Analysis (3EA), engineering error, detailed, effectiveness control, risk assessment

\section{Introduction}

Now, a lot of methods exist that could help us to find hazard and risk assessment in variety fields. Applying these methods is related to users approach. All methods are created based on improvement of controls but potential points for improvement are so extent and we have to select these firstly and apply efficient methods. Based on efficiency of HSE control, basic and detail stages are very important stages. Inherently safer design and eco-friendly design are shown at the stages and any neglect of HSE concepts during design can cause irrecoverable accidents. Based on two attitudes in risk assessment that are inductive and deductive, Engineering Errors and Effect Analysis (3EA) method is an inductive method. 3EA method is based on imagination of accident, what accidents could happen if engineers had errors while preparing project documents. Then it supposes all requirements and standard are available but engineers might not follow them. On the other hand, 3EA helps us to analyze the barriers that prevent errors occurrence.

Mohammad Mahdi Izadi, M.Sc., assistant professor, HSE College, Shahid Beheshti University of Medical Science, Tehran, Iran; HSE manager, Department of Health, Safety, Environment, and Risk, Nargan Co., Tehran, Iran.

Correspondence concerning this article should be addressed to Mohammad Mahdi Izadi, No. 19, Behesht Alley, Bahar Avenue, Sardar-Jangle, Tehran, Iran. 


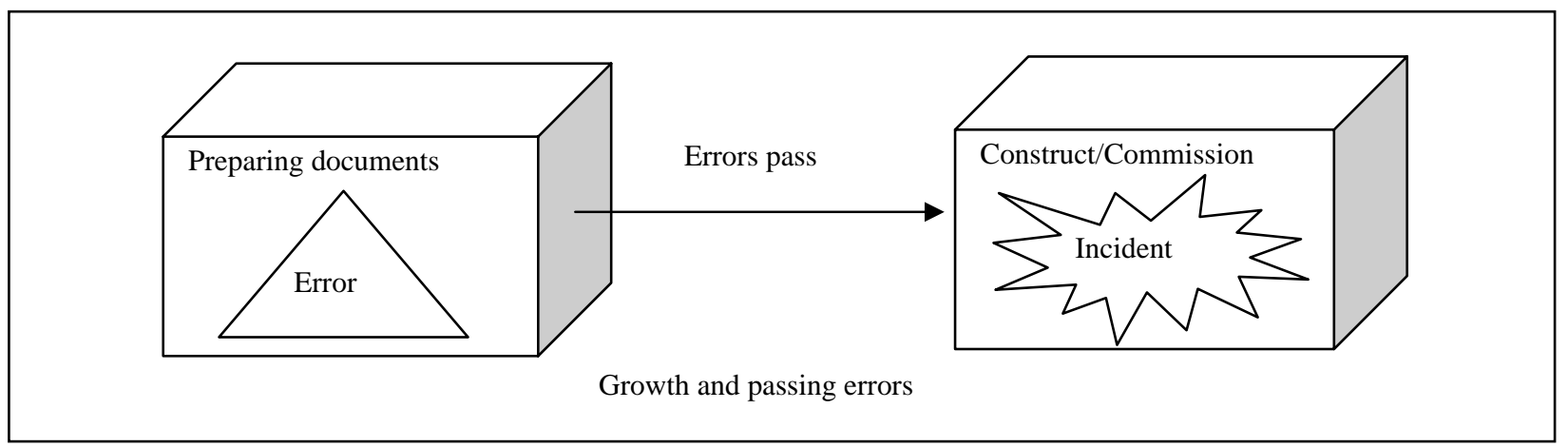

Figure 1. Abbreviations and acronyms.

Here after, 3EA is used instead of "Engineering Errors and Effect Analysis” as abbreviation.

\section{Engineering Errors and Effects Analysis (3EA)}

Consideration of risk types could be helped to find through method. Human errors are so important to make risk that it might be hidden in design processes. Objective of 3EA method is finding human errors at the basic and detail phases. "Hazard" is defined "Error" in the 3EA method. Error means "unfit design". Errors occur because of neglect, irresponsibility, or lack of knowledge. 3EA method could be used in all engineering fields that are related to design consist of electrical, mechanical, process, control and instrument, piping and civil, and so on while preparing project document in basic and detailed phases. Two attitudes exist, safety risk and environmental aspect. Effect analysis is done both on safety risk and environmental aspect. 3EA helps us to categorize project documents based on importance and potential of error occurrence.

\section{EA-Safety Risk Assessment}

In the safety risk assessment based on 3EA, we have four parameters that each of them is categorized to some levels.

(1) Severity: The first parameter is severity that is categorized to five levels. Basis of categorization is human injuries that it is sorted from first grade to fifth grade.

(2) Probability of engineering errors occurrence: It is categorized to five levels form first grade to fifth grade.

(3) Extent of effects: It is categorized to tree levels. Basis of categorization is effects area.

(4) Control effectiveness factor: It is calculated based on two sub-parameters:

(4-1) Error Detect ability: It is categorized to five levels. This sub-parameter is related to how to detect errors while preparing and distributing engineering documents.

(4-2) Compliance with legal: It is categorized to five levels.

Parameters are shown in the below table:

\section{EA-Environmental Aspect Assessment}

The 3EA method is applied for environmental aspect assessment, too. We have four parameters same as safety risk assessment, although descriptions are different. In this approach, we assess environmental impact due to our engineering.

(1) Severity: The first parameter is severity that is calculated based on adding four sub-parameters.

(1-1) Types of emission: This sub-parameter is categorized to five levels. 
(1-2) Adverse effects: This sub-parameter is categorized to five levels. Basis of categorization is effects on fauna, flora, and human.

(1-3) Sustain in environment or energy consumption: This sub-parameter is categorized to three levels. Basis of categorization is degradation of waste and amount of energy consumption.

(1-4) Extent of consequence: This sub-parameter is categorized to three levels. Basis of categorization is boundary of activity area.

(2) Probability of aspect occurrence: The second parameter is probability of aspect occurrence that is categorized to five levels. In this parameter, conditions of environmental aspect occurrence are evaluated that are related to design controls at detailed phase.

(3) Control effectiveness factor: This parameter is related to evaluate effectiveness of control that is designed at detailed phase.

(4) Compliance with legal: The last parameter is compliance with legal that is categorized to five levels.

Table 1

Safety Risk Assessment

\begin{tabular}{lllll}
\hline Severity & Probability & Extent of effects & & Control effectiveness factor \\
\hline A & B & C & Detect ability & Compliance with legal \\
\hline & & D & E \\
\hline
\end{tabular}

Note. Risk number $=\mathrm{A} \times \mathrm{B} \times \mathrm{C}(\mathrm{D}+\mathrm{E})$.

Table 2

Environmental Aspect Assessment Parameters

\begin{tabular}{|c|c|c|c|c|c|c|}
\hline & Seve & erity & & Probability & $\begin{array}{l}\text { Control effectiveness } \\
\text { factor }\end{array}$ & $\begin{array}{l}\text { Compliance with } \\
\text { legal }\end{array}$ \\
\hline $\begin{array}{l}\text { Types of } \\
\text { emission }\end{array}$ & Adverse effects & Sustain/energy & $\begin{array}{l}\text { Extent of } \\
\text { effects }\end{array}$ & \multirow[t]{2}{*}{$\mathrm{E}$} & \multirow{2}{*}{ 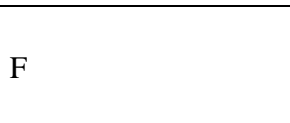 } & \multirow{2}{*}{ 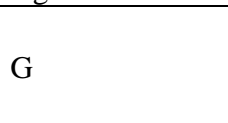 } \\
\hline A & B & $\mathrm{C}$ & $\mathrm{D}$ & & & \\
\hline
\end{tabular}

Note. Risk number $=(\mathrm{A}+\mathrm{B}+\mathrm{C}+\mathrm{D}) \times \mathrm{E} \times \mathrm{F} \times \mathrm{G}$.

\section{Conclusion}

After risk and aspect assessment with 3EA, priority processing of risk numbers must be done. Author has been applying 3EA in seven projects in oil and gas field and five projects are starting to find risk and aspect based on 3EA. This method is applied in Iranian south Pars projects that cause improvement of HSE control. Engineers' awareness about HSE requirements are improved after applying 3EA. Process of preparing project documents is corrected and design led to eco-friendly design. This method helps to us to gather a database of potential points in preparing documents process that could be harmful if these would be missed. Some of engineering documents are prepared based on new procedures. Experience of engineers for preparing some documents is changed and necessity of engineers experience for preparing some documents is accentuated. Results of applying 3EA completely related to HSE concern of companies.

\section{References}

Ericson, C. A. (2005). Hazard analysis techniques for system safety. Hoboken, New Jersey: John Wiley and Sons, Inc.

Everdij, M. H. C., \& Blom, H. A. P. (Eds.). (2010). Safety methods database, version 0.9 (7 December 2010). Maintained by NLR. Retrieved from https://www.nlr.nl/downloads/safety-methods-database.pdf 
Eveson, N. (2004). A new accident model for engineering safer systems. Safety Science, 42, 237-270.

Gort, J., Zwaard, A. W., Stavast, K. I. J., \& Van Alphen, W. J. T. (2010). Learning from accidents, an overview of analysis methods. The Hague: Sdu Uitgevers.

Hollnagel, E. (2004). Barriers and accident prevention. Farnham: Ashgate.

HSE: Investigating accidents and incidents. (2004). A workbook for employers, unions, safety representatives and safety professionals. HSG245.

Lundblad, K., Speciali, J., Woltjer, R., \& Lundberg, J. (2008). FRAM as a risk assessment method for nuclear fuel transportation. Proceedings of The 4th International Conference Working on Safety. Crete, Greece.

Sklet, S. (2002). Methods for accident investigation. Norway: NTNU Norwegian University of Science and Technology.

Smith, D. J. (2001). Reliability, maintainability and risk. Woburn: Butterworth-Heinemann Ltd. 